\title{
Cultivation and Promotion of Postgraduates Scientific Research Ability Based on Practical Training With Advanced Public Instruments
}

\author{
Jiying $\mathrm{Li}^{1}$, Shun $\mathrm{Yao}^{2, *}$ \\ ${ }^{1}$ School of Medicine and Nursing, Changjiang Polytechnic, Wuhan, P. R. China \\ ${ }^{2}$ School of Chemical Engineering, Sichuan University, Chengdu, P. R. China \\ ${ }^{*}$ Corresponding author
}

\begin{abstract}
Based on our working experience in recent years, this paper aimed to explore and discuss the effective way to utilize advanced instrument platforms for postgraduates training together with related latest developing status and teaching reform. With the rapid development of higher education in China society, more and more instruments are being shared and put into practical training; more and more teachers and students are benefiting from them. In the current situation, meaningful exploration is worth carrying out for how to reform the pure classroom teaching mode by scientific means, optimize the teaching resources and improve the level of learning and teaching. Advanced equipment is playing very key role to make graduate students get more coordinated and comprehensive development than undergraduate students.
\end{abstract}

Keywords: Equipment sharing platform, Talent cultivation, Postgraduates, Practical training

\section{INTRODUCTION}

With the rapid development of higher education in China society, the scale of graduate school is expanding continuously; the number of postgraduates in school is growing continuously, and nearly 800,000 graduate students have been enrolled in 2019. However, with the shortage of education and teaching resources in colleges and universities, it is impossible to ensure that postgraduates can carry out sufficient equipment operation and hands-on training. The difference between the actual level of their training and standards of comprehensive talents with strong practical ability together with comprehensive quality required by the society is increasing day by day. Considering this background, the teaching reform for graduate students in colleges and universities cannot be postponed, especially in the new era of emphasizing "learning by doing". As an important goal of graduate students' higher education, ideal usage skills for advanced instruments play an irreplaceable role in cultivating the practical ability and innovative thinking of the majority of postgraduates [1], which is beneficial for improving their scientific research level and should be treated as the common basis of higher education in various countries. Based on the advanced instrument and equipment resources of the colleges together with the analysis \& test departments, it is very necessary to try to train postgraduates systematically to master the use skills of those large-scale instruments shared on the public instrument platform through "learning by doing" on the basis of offering theoretical courses such as new progress of analysis methods and process analysis in the relevant majors. This can solve the problem of insufficient practice for graduate students before they begin their scientific research. It can effectively make up for the current lack for hands-on training in daily teaching, and provide more opportunities for them to operate large-scale instruments and equipment in advance. It will help them integrate theory with practice, and learn standardized operation under the systematic learning at the same time, which can play an irreplaceable key role in promoting the ability of graduate students to comprehensively use analytical skills to solve complex problems. In summary, the implementation of advanced instruments and equipment together with related shared resources are very important to the smooth development of their scientific research and work.

\section{DIFFERENCES BETWEEN UNDERGRADUATE EXPERIMENTS AND GRADUATE PRACTICE}

The cultivation of undergraduates and postgraduates is at two completely different levels and stages. Therefore, there are obvious differences in the settings, contents, key points and methods of teaching. Generally, undergraduates are taught with the most mature and classic theoretical knowledge in the classroom, and what they do in the specialty laboratory are usually confirmatory experiments. After the completion of classroom teaching, their theoretical learning is assisted and strengthened by practical behaviors through the introduction of professional supporting experiments; most of the conventional small low-value 
instruments are used in related experiments, and little advanced equipment can be touched by them. After mastering the basic operation of mature theories and experiments, it is necessary to further broaden the scientific outlook of students, stimulate innovation inspiration, and improve their research ability. However, in the undergraduate experiment activities carried out in most colleges and universities, students complete the operation step by step, there is lack of exploration and independent thinking on the experimental principles and process; most of them only copy experimental handouts and submit experimental data directly as the result. The most obvious evident is that many students are showing the lack of good experimental habits, basic operation and basic skills in the whole process of graduation thesis in their last semester. On the contrary, in the training stage for postgraduates, it is mainly based on solving practical and complex problems in their research and emphasizing the independent completion of design / research / innovation experiments. They need to contact with a large number of large-scale instruments with excellent performance, ultra-high accuracy and sensitivity, which can play an active role in the cultivation of masters and $\mathrm{PhD}$ candidates. Generally, these advanced equipment are expensive meanwhile accurate operation is required strictly, and they are often run and managed by special teachers/staffs. In addition, due to the lack of experimental teaching hours (universities generally do not pay enough attention to the practice teaching of postgraduates in China), many postgraduate students have little chance to contact with them before the beginning or formal scientific studies. The significance of large-scale instruments is still not fully understood, which are the comprehensive products of mathematics, electronics, chemistry, physics, computer and other disciplines. Mastering and using these sophisticated and complex equipment require solid theoretical knowledge and strong operation skills, which is of great guiding significance for graduate students to grasp the academic front and follow their tutors to carry out hot research in disciplines. Therefore, it is urgent to carry out enough practical training before they enter the scientific research laboratory. In this stage, if teachers can make full use of the existing open equipment sharing platform, and apply the creative way of "hardware + virtual simulation training + open fund" to stimulate postgraduates' enthusiasm for mastering these advanced instruments, it will help to cultivate students' practical skills and analysis \& problem-solving abilities. However, most universities carried out "learn by doing" activities directly in scientific research laboratories by the way of senior postgraduates guiding junior graduate students, and students only learn the simple operation of workstation on computers or control terminal under the guidance of a small number of teachers, which cannot improve their deep understanding of the working principle and is more difficult to realize the cultivation of comprehensive scientific research literacy. The practical training with strong pertinence should be included in the postgraduate talent training plan, meanwhile its performance should also be guaranteed strictly.

\section{CONSTRUCTION OF PUBLIC INSTRUMENT PLATFORM IN CHINA UNIVERSITIES}

The extensive use of various instruments and equipment in students is an important means to create an ideal educational environment in colleges and universities, as well as to improve the cultivation ability of innovative talents. After years of construction, the instrument sharing + management platforms of Tsinghua University, Peking University, Zhejiang University, Fudan University and other high-level universities are continually being improved and can be easily browsed from the Internet through ordinary search engines [2]. From the perspective of the existing successful platform, the school-developed sharing systems for instrument and equipment resources can implement automatic management for all users' operation and realize unified information sharing among the instrument and equipment, administrators and users in the whole system efficiently. It can realize the high-speed connection between the network and the database, the management end and mutual visits of the data base together with the communication between users and management end, and finally achieve "management and sharing" dual goals. The instrument administrator can perform information entry, qualification review, use record, remote monitoring and control, charge management and other operations through the browser. The platform user can log in to the equipment appointment management server to perform resource search, instrument appointment, personal information entry, charge details query and other operations. Before using the large-scale instrument sharing platform, it is necessary to use campus card and identity information to register online and become a formal user of the platform. In addition to sending samples for test, the user can also obtain the qualification certificate of central instrument operation through training. Before use, the user logs in to the reservation system to select the operation time; then the background database processes the data of the reservation project, and drives the access control system and the equipment power switch; after that, the user can swipe the card to enter into the laboratories and open the equipment within the specified time. If users encounter difficulties or problems when using the device in working hours, the device administrator can understand the site situation through on-line monitoring and realize remote guidance through the network. If necessary, they will go to solve the problems on-site quickly. This is a powerful system integrating "network reservation + software and hardware linkage + independent testing + remote management".

As a part of "Digital Campus" and "Smart Schoolyard", some colleges and universities also have relatively complete access control units, which integrate the functions of electronic doorplate and unlocking. The electronic doorplate used for the instrument platform can not only display the functions of the equipment, the list of recent appointments and the administrator group, but also have other powerful functions including access unlocking, face 
identification, fingerprint recognition, password unlocking, campus card unlocking and other ways. More importantly, the instrument open sharing system uses the information management function to track, manage and update the reservation status of every equipment in real time, and make statistics and analysis on the utilization rate of all the instruments within one year, the total operation times in school and out of school services, annual charges and other information every year, so as to provide necessary detailed data for the superior management department. Based on the laboratory and equipment management office, Sichuan University (SCU) has established an open sharing system for experimental instruments and equipment [3], which provides comprehensive information and service platform supported by "Virtual Equipment Management Center" (VEMC). At the same time, "Experimental Equipment Sharing Fund" (EESF) and "Experimental Equipment Open
Sharing Expert Group" (EEOSEG) have been set up simultaneously. In addition, an intelligent independent experimental platform system of "Mass Entrepreneurship and Innovation" for all the students in Sichuan University has been established. Furthermore, there is a great project named "Visual Open Sharing Management Platform of Large-scale Equipment" (VOSMPLE) under construction. In addition to these university-level platforms, many secondary schools have also established their own network service platforms for instruments and equipment, such as the public instrument platform of the engineering experiment center and the open simulation system (as shown in Figure 1) belonging to the School of Chemical Engineering. These mutually supported and fully shared super platforms in campus provide great convenience for personnel training and scientific research.

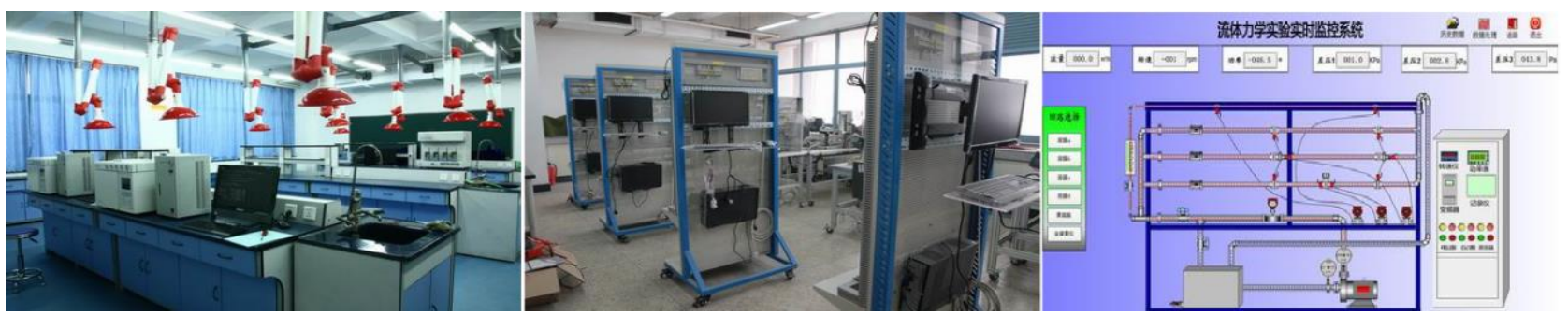

Figure 1 Open instrument sharing platform developed by the School of Chemical Engineering in SCU

\section{DEVELOPMENT PLANS OF INSTRUMENT PLATFORM ACTIVITIES FOR POSTGRADUATES TRAINING}

The important part of the construction of first-class universities is to develop the training ability of China universities for innovative talents, and comprehensive improvement of the education level has become an important reform task of higher education in the new era. Relying on all kinds of shared instrument platforms, the following four strategies are explored by us and suggested for educators: (1) the construction of theoretical teaching auxiliary system, which plays an important role in the formation of students' thinking consciousness, the acquisition of theoretical knowledge, the cultivation of practical ability and other links in innovative education through the practical operation of large-scale instruments and equipment, such as integrating the application of modern analytical methods into the early classroom learning of relevant professional courses. For example, graduate students can form a preliminary impression of these advanced testing methods, understand their functions and know how to use them. In the middle-term study stage, postgraduates should gradually build a systematic theoretical framework of the methods they have learned; the platform help them strengthen the background of professional application, and make students study and use related instruments flexibly according to the tasks \& requirements developed in "inspiration + discussion" teaching, or even grasp the use ability for a variety of equipment in combination. Finally, in the group or single practice link, they are required to carry out instrument selection and targeted operation learning for their interested research directions or problems after overall grasping the theoretical knowledge. In this process, it is especially recommended to dissect and analyze the modern testing methods by using those equipment applied in actual high-level research of each university in order to stimulate the enthusiasm and motivation of students for innovative practice. Finally, the links of "thinking consciousness, basic theory, practical training and professional application" are organically integrated to form a knowledge chain for the cultivation of innovation ability and lay a solid foundation for their subsequent scientific research work.

(2) The implementation of the independent practical training process, that is, on the basis of mastering the theoretical knowledge and methods of modern instruments $\&$ equipment, we can set special practical training link to cultivate the stronger operation ability together with data sorting \& analysis ability of graduate students, which can be regarded as a necessary (optional) course for graduate students' practice (formally preset in the curriculum, with credits) or maneuverable training with adequate teaching hours under flexible arrangement (out of the curriculum, also with various forms of awards and certificates). First of all, the teacher makes a proposition according to the requirements for the operation and data analysis skills of 
large-scale instruments and equipment for postgraduates, and then reasonably distributes the number of people and duration involved in the practice according to the number of equipment sets as well as the operation characteristics. Different from undergraduates, it is suggested to carry out more experiments for single postgraduate. In practice, according to the graduate students' own interests and the assessment of the large-scale instruments that may be used in their future research, each student is suggested to select at least two instruments as the object of operation training, and the teacher will guide them and complete the teaching evaluation during the whole process. Data analysis can be completed independently after operation and submitted on the platform in the form of reports / assignments. Excellent reports will be displayed on the platform as model for more graduate students to learn and reference. Through this kind of specialized practical training, the trainees can further improve the operation skills and data analysis ability and expand their academic vision. It is beneficial to make the distance closer between research work and required instruments and speed up their adaptation process in scientific labs.

(3) Graduate students can also apply for large-scale instrument operation training on their own initiative from time to time. If they pass the training exams organized or supervised by teachers, they can obtain equipment operation qualification certificate. At the same time, the public Instrument Center usually recruits excellent graduate students to participate in daily teaching, management and maintenance activities as part-time assistants of large-scale instruments every academic year (corresponding subsidies will be given according to their working hours), and extra practical training can be obtained by joining administrator's research group for obtaining more chances to understand and use large-scale instruments equipment on public platforms. Through these ways, we can promote graduate students to join the teams of using advanced instruments at a broader level, and properly stand in the perspective of equipment managers to play more flexible roles between "teachers and students" together with "teaching and research".

(4) Considering that the graduate students have more ideal knowledge reservation and hands-on ability, in order to further stimulate their potential in practical training, they can participate in design, assembling, transformation, repair of instruments (including related automation, security monitoring and circuit system, etc.) and the development process of supporting software (including public E-platform, workstation, Apps on mobile phone, etc.) with the approval of teachers. If the task is difficult, graduate students can do most of the work with the help of teachers or full-time personnel, and it is recommended for them to complete the competent work independently. It is suggested that they apply for invention patents or publish academic papers to increase scientific research output, which is expected to promote their scientific research significantly.

(5) With the above foundation, graduate students are encouraged to apply for scientific research projects and participate in discipline competitions actively relying on the public equipment platform. Sichuan University has set up a Scientific Research \& Innovation Fund for postgraduates, and tens of thousands of yuan will be invested for each approved project. Students are also encouraged to use large-scale instruments in national, provincial and school-level innovation training projects to expand the understanding of professional knowledge and improve the accomplishment of scientific research. In addition, those projects closely related to instruments and equipment can also apply for the support from "Experimental Equipment Sharing Fund" mentioned above. Graduate students can not only form a team, but also lead undergraduates to participate in relevant activities, consolidate the analysis and test means learned in practical training, and obtain more innovative results with higher academic level, so as to carry out multi-level innovative research activities. According to our practice in our school during the last decade, there are many good projects winning the awards in the national and provincial "Challenge Cup" innovation competition, chemical experimental skill competition, national college students energy conservation and emission reduction competition, pharmaceutical forum and other competitions every year. At same time, the number of SCI-indexed papers published by graduate students under the support of the public instrument platform reaches dozens per year.

\section{SUMMARY}

Obviously, the role of advanced equipment in higher education is growing continuously, which has become an indispensable part of modern education. The instruments sharing system is beneficial to implement convenient training and service for postgraduates, and it is supporting various teaching reform activities for talent cultivation. After years of construction, large-scale equipment sharing platform is expected to stimulate students' enthusiasm for research activities by using advanced instruments, and then cultivate students' practical ability, analysis and problem-solving ability. At the same time, the extensive use of similar systems in students is also an important means to create a university education environment and improve the quality of innovative talents training.

\section{ACKNOWLEDGEMENTS}

This research was financially supported by Personnel Training Quality \& Teaching Reform Project of Higher Education in Sichuan Province (2018 2020), 2019 Project of skilled personnel training research center in Hubei province: Research on the experiential teaching mode in the teaching of traditional Chinese medicine in higher vocational Colleges and 8th "Reform 
Project of Higher Education in New Century" of Sichuan University (2018).

\section{REFERENCES}

[1] Information on http://www.chinamae.com/shownews_101742_2.html

[2] Information on http://yqgx.tsinghua.edu.cn/webSite/websiteAction.do? $\mathrm{ms}=\mathrm{goToIndex}$

[3] Information on http://vemc.scu.edu.cn/sfw/e?page=shareequ. shareequ\& $\underline{\mathrm{cid}=6}$ 